\title{
Vehicle Collisions Cause Differential Age and Sex-Specific Mortality in Mule Deer
}

\author{
Daniel D. Olson, ${ }^{1}$ John A. Bissonette, ${ }^{2}$ Patricia C. Cramer, ${ }^{3}$ Kevin D. Bunnell, ${ }^{4}$ \\ Daniel C. Coster, ${ }^{5}$ and Patrick J. Jackson ${ }^{6}$ \\ ${ }^{1}$ Oregon Department of Forestry, 2600 State Street, Salem, OR 97310, USA \\ ${ }^{2}$ Department of Wildland Resources, Utah State University, 373 BNR, Logan, UT 84322, USA \\ ${ }^{3}$ Department of Wildland Resources, Utah State University, 213 BNR, Logan, UT 84322, USA \\ ${ }^{4}$ Utah Division of Wildlife Resources, 1470 N Airport Road, Cedar City, UT 84720, USA \\ ${ }^{5}$ Department of Mathematics and Statistics, Utah State University, 219 ANSC, Logan, UT 84322, USA \\ ${ }^{6}$ Department of Wildland Resources, Utah State University, 167 BNR, Logan, UT 84322, USA
}

Correspondence should be addressed to Daniel D. Olson; dolson22@gmail.com

Received 19 June 2014; Revised 21 October 2014; Accepted 22 October 2014; Published 11 November 2014

Academic Editor: David R. Breininger

Copyright (C) 2014 Daniel D. Olson et al. This is an open access article distributed under the Creative Commons Attribution License, which permits unrestricted use, distribution, and reproduction in any medium, provided the original work is properly cited.

As roads continue to be built and expanded, it is important that managers understand the effects that vehicle-related mortality can have on the population dynamics of wildlife. Our objective was to examine the frequency of mule deer (Odocoileus hemionus) vehicle collisions to determine if different demographic groups showed differential susceptibility to mortality when compared with their proportion in the population. We also compared vehicle collision rates of mule deer, elk (Cervus canadensis), and moose (Alces alces) to determine their relative vulnerability to vehicle collisions. We found that $65 \%$ of mule deer involved in vehicle collisions were female; of those, $40 \%$ were adult does $\geq 2$ yrs. When we compared the proportion of bucks, does, and fawns killed in vehicle collisions to surveys of live deer, we found that bucks were killed at rate of 2.1-3.0 times their proportion in the population. Additionally, when we compared vehicle collision rates for 2010 and 2011, we found that mule deer were 7.4-8.7 times more likely to be involved in collisions than elk and 1.2-2.0 times more likely than moose. However, we were unable to detect a negative correlation $(P=0.55)$ between mule deer abundance and increasing traffic volume.

\section{Introduction}

Roads are being built and expanded throughout the developed world to accommodate the increasing human population and demand for transportation of people, goods, and materials [1-3]. An IEA 2013 report [4] suggested the following: the world will need to add nearly 25 million paved road lane $\mathrm{km}$ ( $\sim 60 \%$ increase) between 2010 and 2050; between 45000 and $77000 \mathrm{~km}^{2}$ of new parking spaces will be added to accommodate passenger vehicle stock growth; global travel in 2050 will double that of 2010 travel levels; passenger travel will account for $70 \%$ of this growth; and $\sim 90 \%$ of travel growth is expected in developing countries. Laurance et al. [5] estimated that the total length of the projected new roads is equivalent to encircling the earth $\sim 600$ times. Clearly, it is increasingly important to understand the effects that roads have on wildlife; those effects appear to be overwhelming negative for most species [6-9]. Deer are commonly involved in vehicle collisions in Europe, North America, and Japan [10-12]. In the United States alone, there are an estimated 1-2 million vehicle collisions with large animals annually, most of which involve deer, that result in $>\$ 8$ billion (USD) in damages and $>200$ human fatalities [1315]. Additionally, vehicle collisions are nearly always fatal for deer [16].

Mule deer occur throughout western North America and are regularly involved in vehicle collisions [17-19]. The effects that vehicle-related mortality has on population dynamics of mule deer depend not only on the number of individuals killed but also on the demographic groups involved. Deer populations are commonly classified into 
demographic groups based on sex and life stage characteristics (e.g., fawns, yearlings, and adults) with distinct fecundity and survival rates [20]. In mule deer populations, adult females are the most important demographic group to population growth [21], because they have high survival rates and nurse fawns until the termination of parental care [22, 23]. Male demographic groups are relatively less important to population growth, because mule deer are polygynous and males do not contribute to the parental care of fawns $[22,24]$. The age of adult deer can also influence their contribution [25], because survival and reproductive rates are highest for prime-aged individuals (2-7 yrs). As individuals age, survival and reproductive rates decline [25-28]. Factors such as tooth wear can contribute to senescence in deer $[29,30]$. Overall, mortality factors that remove prime-aged females potentially exert a stronger influence on population potential of deer than those that primarily remove senescent females. Further, changes in population density have been suggested to influence sex ratios over longer time periods and thereby indirectly influence specific age and sex demographic group vulnerability to wildlife vehicle accidents (WVCs) [31]. However, recent work [32] has suggested that understanding the underlying spatiotemporal factors is key to understanding the reasons for WVCs. Although moose density was most important in explaining WVCs in Norway, traffic volume and snow depth were also implicated. The increase in the number of red deer (Cervus elaphus) killed on Norwegian roads was found to be primarily an effect of increasing population size [33]. Annual vehicle collision rates vary between ungulate species due to differences in behavior and habitat use [34]. For instance, several studies have shown that elk tend to avoid roads [35-38], which may in turn decrease their vulnerability to vehicle collisions. A few recent studies have reported that mule deer actually select habitats near roads [35, 36, 39 ], which predisposes them to vehicle collisions. Vehicle collisions rates of deer species with overlapping distributions have rarely been compared [11], but if differences exist, it would be beneficial to examine the causes of those differences and tailor mitigation to individual species.

Deer vehicle-collisions (DVCs) have negatively impacted some deer populations. In Florida, $50-74 \%$ of mortality for the endangered Key deer (Odocoileus virginianus clavium) was due to vehicle collisions [40]. Additionally, vehicle collisions were also the leading cause of death $34 \%$ of mortality) for female mule deer in northern Utah, and lower than average survival rates were reported [41]. However, for most deer populations, DVCs appear to play a minor role in population dynamics. For example, white-tailed deer (Odocoileus virginianus) are commonly involved in vehicle collisions [42-44]; nevertheless, the species has continued to increase in abundance and expand its distribution in North America $[45,46]$.

In Utah, mule deer are frequently killed in vehicle collisions and deer carcasses are regularly observed on roads [47], and as a result there is concern from management agencies, environmental and sportsmen organizations, and the public that DVCs may negatively impact populations. Our objective was to examine the frequency of mule deer (Odocoileus hemionus) vehicle collisions to determine if different demographic groups showed differential susceptibility to mortality when compared with their proportion in the population. Additionally, we wanted to assess the percentage of prime-aged individuals being removed. We also compared vehicle collision rates of mule deer, elk, and moose in Utah to determine the relative vulnerability of mule deer to vehicle collisions. Finally, we examined trends in mule deer abundance and traffic volumes to determine if roads were affecting abundance at the statewide scale extent.

\section{Materials and Methods}

2.1. Study Area. The study was conducted in the state of Utah $\left(219,807 \mathrm{~km}^{2}\right)$, which is located in the southwestern United States on the western edge of the Rocky Mountains (Figure 1). Much of the state is semiarid (127-381 mm precipitation) [48]. Utah is the second driest state in the United States [49]. Topography, however, is highly variable (663-4,413 m) and precipitation increases with elevation [50]; as a result, some high elevation areas may receive in excess of $>1,473 \mathrm{~mm}$ of precipitation [48]. The majority of Utah is comprised of three ecoregions: the Colorado Plateau, the Wasatch and Uinta Mountains, and the Central Basin and Range [51]. The landscape is ecologically diverse with vegetation cover types that vary from salt desert shrub to alpine tundra [52]. Utah is inhabited by a suite of ungulates that include mule deer, elk, moose, and white-tailed deer [46]. Of those species, mule deer were the most abundant ( $\sim 300,000$ individuals) and widely distributed [53], and their range coincided with or was adjacent to nearly all mountainous areas and major human population centers in the state. Elk were less abundant ( 75,000 individuals) than mule deer, but elk abundance has consistently grown over the past decade [53]. The distribution of elk closely resembled that of mule deer but was more restricted in some locations. Moose were far less abundant ( 2,700 individuals) than both mule deer and elk, and their range was generally limited to the central and northern portions of the state [53] but their distribution generally overlapped mule deer and elk distributions. White-tailed deer existed in very limited numbers in the extreme northern portion of Utah [46], and no estimates of abundance were available because populations were not monitored by the Utah Division of Wildlife Resources (UDWR). All deer species are harvested in Utah, with harvest being strongly biased towards males [53].

In Utah, $75 \%$ of the land area is federally or state owned, and, as a result, much of the state is rural [54]. Utah, however, is the 3rd fastest growing state in the United States and is rapidly becoming urbanized $[55,56]$. The growing human population has increased demand for transportation, and traffic volumes have doubled in the past 30 years [57]. In $2010,42.8$ billion $\mathrm{km}$ were driven on $73,413 \mathrm{~km}$ of roads [57, 58]. Deer-vehicle collisions are a considerable public safety concern in Utah that has resulted in $>\$ 7$ million (USD) in damages each year [59]. In the past, most reported DVCs in Utah have involved mule deer [47].

2.2. Demographics. To quantify the demographics of mule deer killed in vehicle collisions, we conducted carcass surveys 


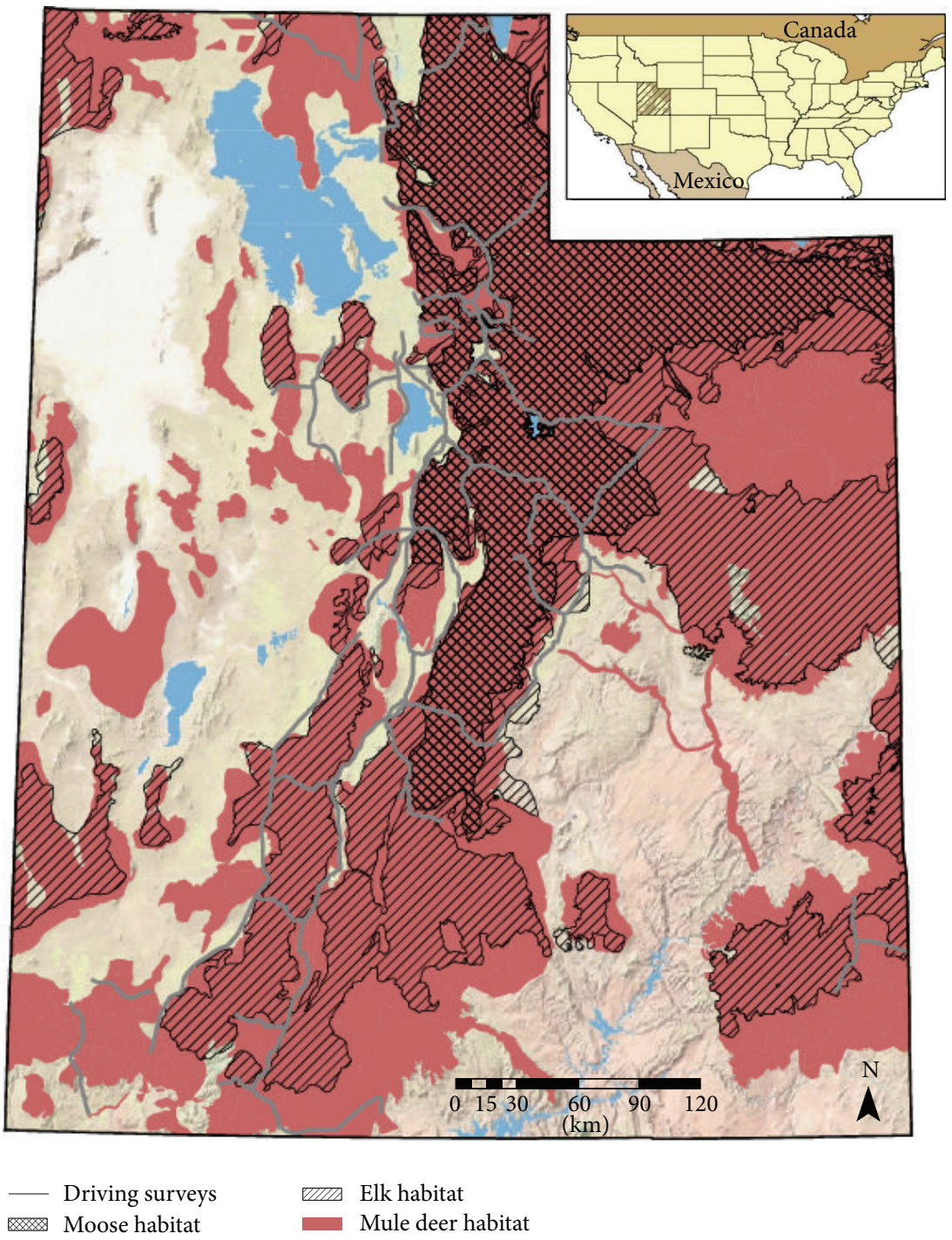

FIGURE 1: Mule deer, elk, and moose habitat in Utah, as well as the roads that were surveyed for carcasses of those species.

throughout northern, central, and southeastern Utah. Carcass survey transects $(4.8 \mathrm{~km})$ were selected using a proportional sampling design [60]. Transects were surveyed every 14 days by trained technicians employed by Utah State University using All-Terrain Vehicles (ATVs). During a carcass survey, the technician functioned as both driver and observer. ATVs were driven at $8-16 \mathrm{~km} / \mathrm{h}$ on the shoulder and the median of roads within transects. Technicians recorded carcass locations using a Garmin GPS unit (Model eTrex Legend H, Garmin International, Inc., Olathe, Kansas, USA). They also documented the sex and stage class of carcasses (fawn, yearling, and adult) observed. All carcasses detected during surveys were marked with an orange, serial numbered tag that was placed around the hind leg to insure that carcasses were not double counted during future surveys. Technicians also examined and marked all deer carcasses that were opportunistically observed while driving to and from survey transects. Carcasses for which the stage class and sex could not be determined were excluded from the analysis. We tested for differences in the proportion of deer that were in each demographic using chi-square tests $(\alpha=0.05)$. All statistical analyses for this study were performed in $\mathrm{R}(\mathrm{R}$ 2.14.1, http://www.cran.r-project.org./, accessed may 15, 2012) [61].

To determine if the frequency in which deer demographic groups were involved in vehicle collisions was proportional to the deer population, we compared carcass survey data to classification surveys of live deer. Classification surveys were conducted by Utah Division of Wildlife Resources (UDWR) biologists during late fall (November-December) when deer were congregated on winter ranges. Deer were classified as bucks (males $\geq 1.5$ yrs old), does (females $\geq 1.5$ yrs old), and fawns (males and females $\leq 0.5$ yrs old). To make carcass survey data comparable to UDWR classification surveys, we combined adult and yearling groups for both males and females from carcass surveys to create buck and doe groups. 
Additionally, we counted male and female fawn groups as one group (fawns). Classification data used for comparison was obtained from deer management units that coincided with carcass survey locations. We tested for differences between carcass survey data and live classifications using chi-square tests $(\alpha=0.05)$.

To estimate the age of adult deer, we extracted lower incisors from carcasses and sent them to Dr. R. Larsen's lab at Brigham Young University (Provo, Utah, USA) for cementum annuli analysis. Teeth were cross sectioned and stained, and age estimates were generated using standard techniques [62]. The accuracy of age estimates using this method is typically $>90 \%$ for mule deer [63]. Age estimates were reported as the base year, and June 15th was used as transition date from one year to the next because that was the peak fawning date in Utah [27]. Because age distributions were skewed for both males and females, we reported medians instead of means and we tested for differences using a nonparametric Wilcoxon rank-sum test $(\alpha=0.05)$.

2.3. Vehicle Collision Rates. To quantify vehicle collision rates for mule deer, elk, and moose, we used carcass survey data that were collected by Utah Department of Transportation (UDOT) contractors using automobiles. Automobile surveys have been conducted in Utah since at least 1998 [19]. UDOT contractors drove $\sim 2,750 \mathrm{~km}$ of roads 2 times per week throughout the year. Surveys were generally performed by a single person, who acted as driver and observer. Survey vehicles were driven at the posted speed limit. If the road had multiple traffic lanes, the survey vehicle was driven in the slow lane, nearest to the shoulder of the road. Undivided roads were surveyed in only one direction, while divided roads with a median were surveyed in both directions. During surveys, UDOT contractors removed all carcasses that were detected on the road surface, the median, and the road shoulder out to the reflective highway markers. They kept detailed records of the species removed and their locations. Driving surveys were minimum estimates of vehicle collision rates, because they do not account for carcass detection probabilities. We also quantified the overlap of mule deer, elk, and moose habitat using ArcGIS 10.1 and distribution layers that were generated by the UDWR for each species [64].

2.4. Mule Deer Abundance and Traffic Volumes. Mule deer abundance was estimated annually by the UDWR using a combination of ground and aerial counts for deer management units throughout the state; however, no measures of uncertainty were reported for abundance estimates [53]. Traffic volume data were obtained from the Utah Department of Transportation for the study area [65]. Traffic volumes were reported by UDOT as average annual daily traffic (AADT) during each calendar year.

\section{Results}

3.1. Demographics. From July 2010 to December 2011, we examined 1,257 carcasses of deer that had died within the road right of way and had injuries consistent with being involved

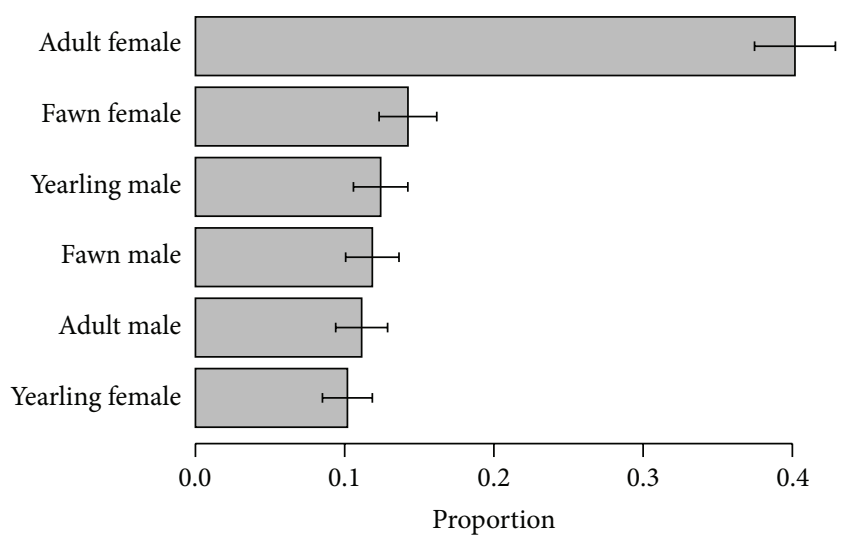

Figure 2: The proportion of each mule deer demographic group observed in carcass surveys conducted in Utah. Error bars represent $95 \%$ confidence intervals $(\alpha=0.05)$.

in a vehicle collision. As expected, the frequencies with which deer demographic groups were involved in vehicle collisions differed between groups $\left(\chi^{2}[2, n=1,257]=41.9, P<\right.$ $0.01)$. Adult females comprised the largest group at $40 \%$, a rate that was 2.8-3.9 times more than any of the other demographic groups whose collision rates ranged between $10 \%$ and $14 \%$ (Figure 2). Collectively, female adults, yearlings, and fawns represented $65 \%$ of all deer carcasses. We obtained age estimates for 524 adult mule deer that were killed in vehicle collisions. Ages of female and male deer differed $(W=29118, P<0.01)$; the median age for females was 4 yrs and, for males, it was 3 yrs (Figure 3). Nearly, all adult females (98\%) and males (98\%) were between 2 and 7 yrs old and considered prime-aged individuals. The oldest observed female was 13 yrs old; the oldest male was 9 yrs old. When we compared the proportion of bucks, does, and fawns in carcass surveys to those in classification surveys of live deer, we found that they differed for both fall $2010\left(\chi^{2}[2, n=18,221]=\right.$ 40.9, $P<0.01)$ and fall $2011\left(\chi^{2}[2, n=16,426]=38.4\right.$, $P \leq 0.01)$. During both years, there were fewer fawns $(-13$ to $-28 \%)$ and does $(-10$ to $-16 \%)$ in carcass surveys than in live surveys, but $95 \%$ confidence intervals for those groups overlapped indicating that the results were not statistically significant (Figure 4). The proportion of bucks did differ significantly and was 205-296\% higher in carcass surveys than live surveys.

3.2. Comparative Vehicle Collision Rates by Species. The distribution of mule deer, elk, and moose in Utah overlaps to a large degree, with $96 \%$ of elk habitat and $99 \%$ of moose habitat corresponding with the distribution of mule deer (Figure 1). However, vehicle collisions rates varied widely among species (Figure 5). Mule deer experienced the highest vehicle collision rates during both $2009-2010$ (18.3 per 1,000 deer) and 2010-2011 (18.3 per 1,000 deer), which were 739$869 \%$ higher than those experienced by elk (2.1-2.5 per 1,000 elk) and $119-197 \%$ than those experienced by moose (9.3-15.3 per 1,000 moose). 


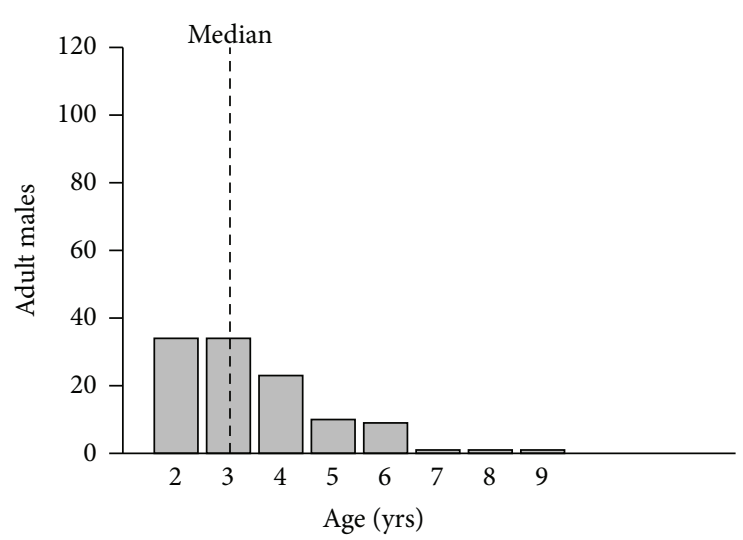

(a)

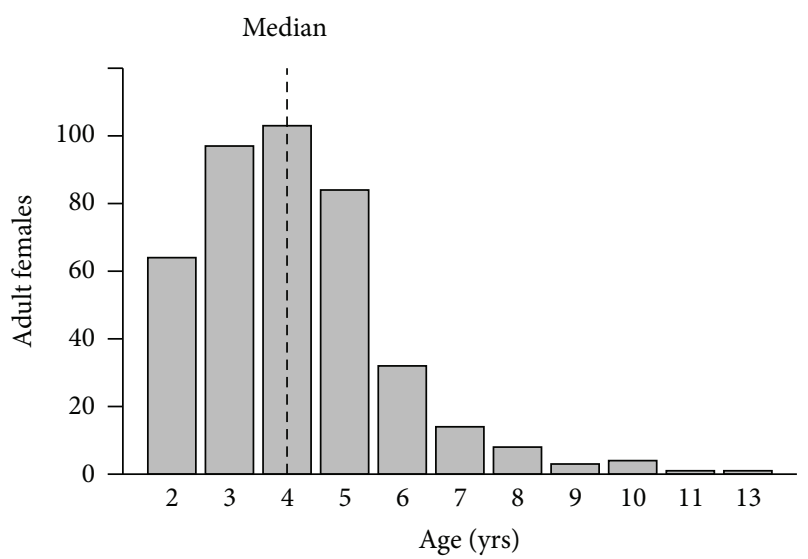

(b)

Figure 3: Age estimates in years for adult female $(n=411)$ and adult male $(n=113)$ mule deer observed in carcass surveys in Utah. Median age estimates for each group are indicated by vertical dashed lines.

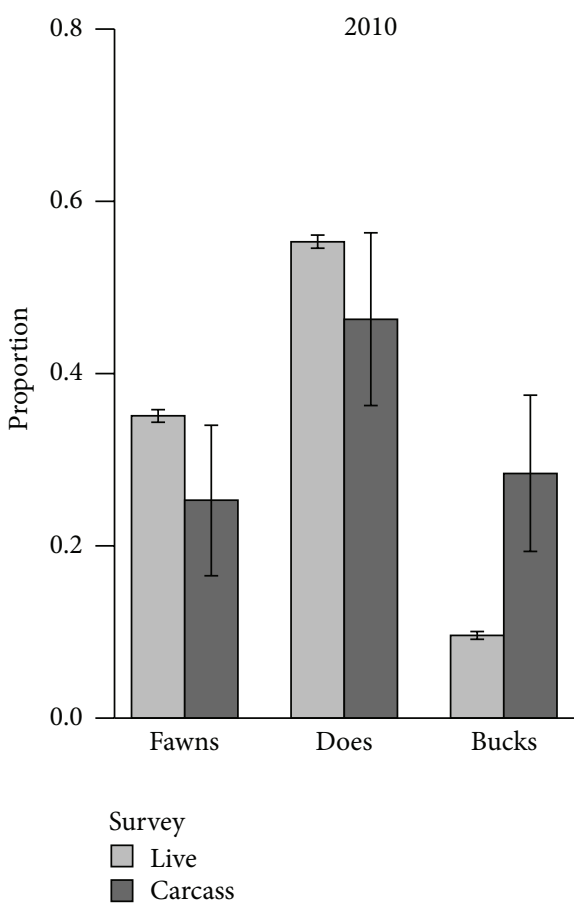

(a)

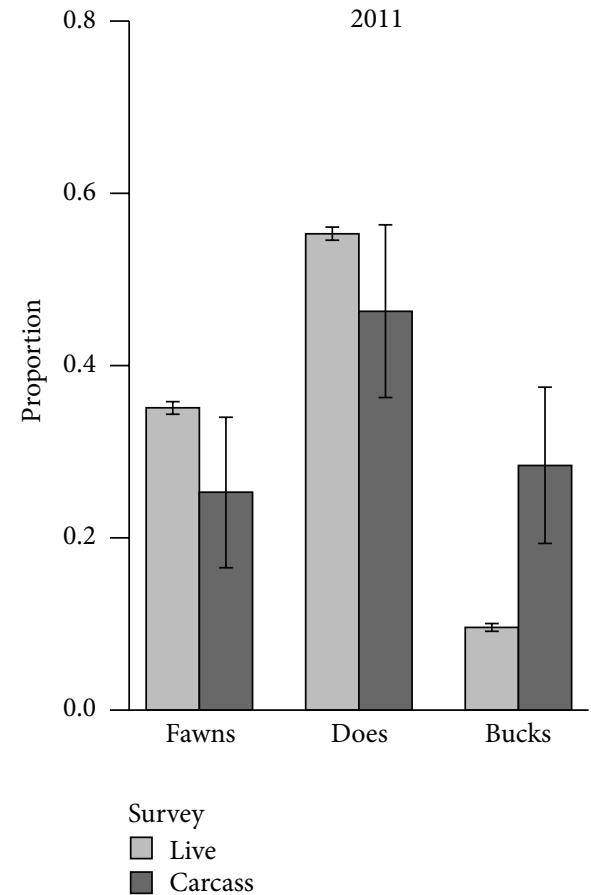

(b)

Figure 4: A comparison of mule deer bucks, does, and fawns in carcass surveys to those in classification surveys of live deer during fall 2010 and fall 2011 in Utah. Error bars represent 95\% confidence intervals $(\alpha=0.05)$.

3.3. Mule Deer Abundance and Traffic Volumes. From 1992 to 2011, mean mule deer abundance in Utah was estimated at 291,044 individuals $(n=20, \mathrm{SD}=26,359)$ [53]. Abundance peaked in 1992, but declined to its lowest point in 1993 due to severe winter weather (Figure 6). Although mule deer abundance was highly variable over the 20-year period, there was no linear trend in abundance $\left(F_{1,18}=0.28, P=0.60\right.$, and $\left.R^{2}=0.02\right)$. During the same time period, mean traffic volume for the state was 37.3 billion $\mathrm{km} /$ year $(n=20, \mathrm{SD}=$ 4.0). The lowest traffic volumes occurred in 1992 and the highest in 2007 (Figure 6). There was a positive linear trend in traffic volume $\left(F_{1,18}=178.8, P \leq 0.01\right.$, and $\left.R^{2}=0.91\right)$, and traffic volumes increased $2 \%$ annually over the 20 -year period. There was no evidence that mule deer abundance and traffic volumes were correlated at the statewide scale extent $\left(F_{1,18}=0.38, P=0.55\right.$, and $\left.R^{2}=0.02\right)$.

\section{Discussion}

Deer demographic groups vary in their contribution to population growth [21]. As a result, the effect that DVCs have on population growth is determined not only by the number 


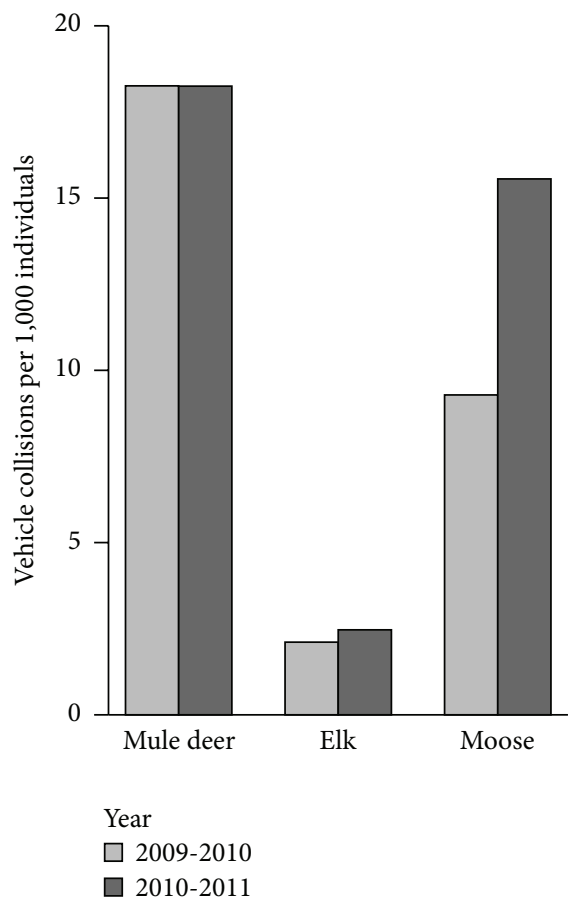

FIGURE 5: Vehicle collision rates (per 1,000 individuals) for mule deer, elk, and moose during 2009-2010 and 2010-2011 in Utah.

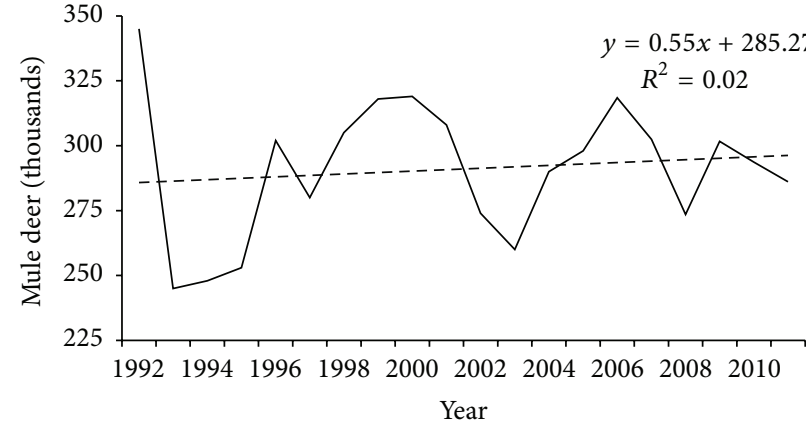

(a)

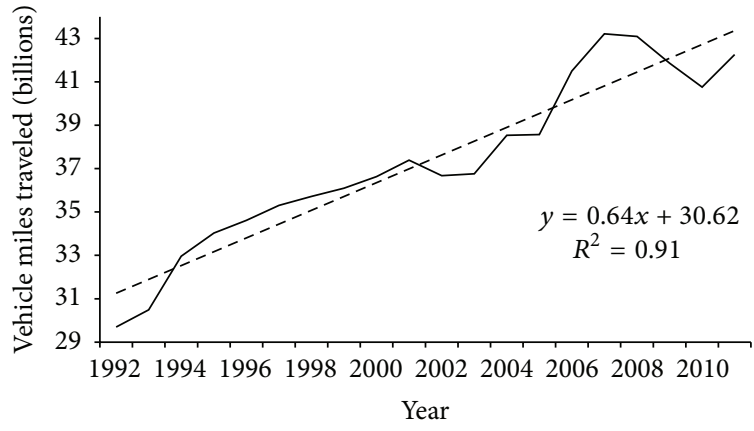

(b)

FIGURE 6: Mule deer abundance and traffic volume (vehicle miles traveled) estimates in Utah for 1992-2011.

of deer that are killed but also by the demographic groups that are differentially impacted. In polygynous species, females are more vital to population growth than are males. In deer, adult female deer are generally considered the most important demographic group [21]. We found that nearly two-thirds of mule deer killed in vehicle collisions in Utah were female and $40 \%$ were adult females. Our data suggest that vehicle collisions could have a strong negative influence on deer abundance, because a high percentage of vehicle collisions involved females, most of which were adult females.

It appears common that most vehicle collisions involve female deer. A previous study in central Utah reported that $68 \%$ of deer killed were female, which was almost identical to the results reported here [18]. Studies of white-tailed deer have reported similar findings with the frequency of vehicle collisions involving female deer ranging from 58 to $66 \%$
$[16,66]$. Female deer are more frequently involved in vehicle collisions because, in most hunted deer populations, the demographics are strongly skewed towards females [22]. If we assumed a fawn sex ratio of 1:1 [27], then classification surveys of live deer indicated that $71-73 \%$ of the population consisted of females in Utah, which was only slightly higher than what we observed in carcass surveys $(66 \%)$. The femalebiased population structure in Utah is largely the result of the male-biased harvest strategy. During our study, 7.6-11.6 times more males were harvested than females, while males represented only $27-29 \%$ of the population [53]. In Wyoming and central Utah, research has also suggested that the female deer were killed in vehicle-collisions in proportion to their frequency in the population $[67,68]$. Furthermore, populations of white-tailed deer that were experimentally reduced exhibited a proportional decrease in DVCs, indicating that 
DVCs are a reflection of the deer population density in general [44].

Although the composition of DVCs generally resembles population structure, there are times when certain demographic groups may be more prone to vehicle collisions [33]. For example in Wisconsin, the number of DVCs involving white-tailed deer bucks increased sharply during fall (October-November), presumably in response to bucks increasing their movement rates to search for females during the breeding season [69]. The results from our study support that pattern, as the proportion of mule deer bucks killed in vehicle collisions, was 2-3 times their frequency in the fall population. However, a previous study conducted in central Utah reported that mule deer bucks were killed at a rate that was 2 times their frequency in the population not only during the fall season but throughout the year, suggesting that the pattern of increased buck mortality may not be strictly seasonal [67]. Regardless of whether increased buck mortality is a seasonal or annual pattern, managers may wish to explicitly consider vehicle collision losses when setting harvest quotas because bucks are already heavily harvested in Utah and other western states.

In addition to the fact that a high percentage of vehicle collisions involved adult females, nearly all (98\%) of the adult deer killed were prime-aged individuals (2-7 yrs.). A similar result was reported in Central Utah, where all adult deer (100\%) involved in vehicle collisions were primeaged individuals. The implications are subtle but important, because prime-aged females typically have the highest survival and reproductive rates. For example in Utah, primeaged females were reported to have $18 \%$ higher pregnancy rates and 30\% higher fecundity rates than senescent females [25]. Additionally, data from southeast Idaho indicate that survival rates decrease $\sim 4 \%$ annually for senescing female mule deer [70]. The effect that vehicle collisions could have on population abundance is likely strengthened because most adult females killed were prime-aged.

Mule deer also appeared to be more prone to vehicle collisions than other ungulate species in Utah. In our study area, the distribution of elk and moose largely coincided with that of mule deer, but vehicle collision rates for mule deer were 7.4-8.7 times higher than those for elk and 1.22.0 higher than those for moose. However, the comparative vehicle collisions rates that we reported were not corrected for carcass detection because even though we have detection probabilities for mule deer, no detection probabilities were available for moose and elk, we chose not to conduct a biased comparison. Previous studies have indicated that carcass surveys generally underestimate (i.e., detection is $<1$ ) the actual number of animals killed in vehicle collisions [71]. In an associated study in Utah, detection of mule deer carcasses during driving surveys was estimated to be only 0.41 [72]. Carcass detection rates for elk and moose are largely unknown and should be the focus of future research. If we could have corrected estimates for detection bias for moose and elk, the disparity in vehicle collision rates would likely have increased.

We know of no other peer-reviewed studies that have compared vehicle collision rates for mule deer, elk, and moose with overlapping distributions. The only comparable study that we are aware of was conducted in Norway, where vehicle collision rates for roe deer (Capreolus capreolus) were 3.2 times higher than those for red deer and 1.5 times higher than those for moose, suggesting a pattern similar to what we observed in Utah [11]. Roe deer are smaller than mule deer but fill a comparable ecological niche in Europe [73]. Some of the dissimilarity in vulnerability between the species is no doubt related to species-specific behavioral responses to roads. For example, studies that have evaluated habitat selection by elk with respect to roads have reported consistently that elk generally avoid roads $[37,74,75]$. However, similar studies conducted on mule deer have not produced consistent results. Several studies have documented that mule deer avoid roads [76-80], but an equal or greater number of studies have reported that mule deer respond neutrally $[78,80,81]$ or, in many cases, may actually select habitats near roads $[35,36$, $39,82-84]$. If mule deer are selecting habitats near roads and elk are avoiding roads, it may help explain a great deal of the differences in vehicle collision rates between the species.

The reasons why mule deer select habitat near roads in some areas are still uncertain. One explanation that has been put forth is that elk, which are socially dominated to mule deer and increasing in abundance, may be displacing deer from habitats that are farther from roads $[35,36]$. This hypothesis is reasonable but still needs to be tested experimentally. Additionally species-specific responses of deer and elk to weather conditions may also be contributing to the disparity in vehicle collision rates, because mule deer are impacted by winter weather, especially snow depth, to a greater extent than elk. Snow accumulation may force mule deer into lower elevation habitats that are near roads with high traffic volumes, thus increasing vehicle collision rates [85].

Although it is uncommon for vehicle collisions to cause deer abundance to decline, some populations have been significantly affected by vehicle-related mortality [40, 41, 67]. In our study area, we were able to establish that a high percentage of vehicle collisions involved adult females and that mule deer were more vulnerable to vehicle collisions than other deer species, but we were unable to demonstrate that vehicle collisions were causing a decrease in mule deer abundance. Over the past 20 years in Utah, traffic volumes have increased $42 \%$ but the long-term trend for mule deer abundance has remained stable. Given that deer populations can sustain moderate removal levels [86], it is probable that vehicle-related mortality levels for mule deer are not yet high enough across the state to cause population decline, even though it has been estimated that $2-5 \%$ of the mule deer population was being killed in vehicle collisions each year in Utah [72]. Additionally, mitigation measures such as wildlife crossings and exclusionary fencing have been used in Utah since the 1970s to improve motorist safety and reduce deer mortality $[47,87,88]$. It is likely that mitigation has partially offset some of the effects of increasing traffic volumes and vehicle-related mortality on mule deer. As the road network is expanded and traffic volumes continue to increase, mitigation will likely become more crucial in reducing the negative effects of roads on deer. 


\section{Conflict of Interests}

The authors declare that there is no conflict of interests regarding the publication of this paper.

\section{References}

[1] U.S. DOT, 2010 Status of the Nation's Highways, Bridges, and Transit: Conditions and Performance, United Department of Transportation, Washington, DC, USA, 2010.

[2] P. Larsson, S. W. A. Dekker, and C. Tingvall, "The need for a systems theory approach to road safety," Safety Science, vol. 48, no. 9, pp. 1167-1174, 2010.

[3] R. T. T. Forman, D. Sperling, J. A. Bissonette et al., Road Ecology: Science and Solutions, Island Press, Washington, DC, USA, 2003.

[4] J. Dulac, "Global Land Transport Infrastructure Requirements: estimating road and railway infrastructure capacity and costs to 2050," Int Energy Agency, 2013.

[5] W. F. Laurance, G. R. Clements, S. Sloan et al., "A global strategy for road building," Nature, vol. 513, pp. 229-232, 2014.

[6] L. Fahrig and T. Rytwinski, "Effects of roads on animal abundance: an empirical review and synthesis," Ecology and Society, vol. 14, article 21, 2009.

[7] I. A. Roedenbeck, L. Fahrig, C. S. Findlay et al., "The Rauischholzhausen agenda for road ecology," Ecology and Society, vol. 12, no. 1, article 11, 2007.

[8] S. C. Trombulak and C. A. Frissell, "Review of ecological effects of roads on terrestrial and aquatic communities," Conservation Biology, vol. 14, no. 1, pp. 18-30, 2000.

[9] R. T. T. Forman and L. E. Alexander, "Roads and their major ecological effects," Annual Review of Ecology and Systematics, vol. 29, pp. 207-231, 1998.

[10] M. Noro, "Analysis of deer ecology and landscape features as factors contributing to deer-vehicle collisions in Hokkaido, Japan," in Proceedings of the Transportation Research Board 89th Annual Meeting, Washington, DC, USA, January 2010.

[11] G. W. T. A. G. Bruinderink and E. Hazebroek, "Ungulate traffic collisions in Europe," Conservation Biology, vol. 10, no. 4, pp. 1059-1067, 1996.

[12] J. W. Ng, C. Nielsen, and C. C. S. Clair, "Landscape and traffic factors influencing deer-vehicle collisions in an urban environment," Hum-Wildl Conflicts, vol. 2, pp. 34-47, 2008.

[13] M. R. Conover, Resolving Human-Wildlife Conflicts: The Science of Wildlife Damage Management, CRC Press, Boca Raton, Fla, USA, 2001.

[14] M. P. Huijser, P. T. McGowen, J. Fuller, A. Hardy, and A. Kociolek, Wildlife-Vehicle Collision Reduction Study: Report to Congress, Western Transportation Institute, Bozeman, Mont, USA, 2008.

[15] R. L. Langley, S. A. Higgins, and K. B. Herrin, "Risk factors associated with fatal animal-vehicle collisions in the United States, 1995-2004," Wilderness \& Environmental Medicine, vol. 17, no. 4, pp. 229-239, 2006.

[16] R. E. Allen and D. R. McCullough, "Deer-car accidents in southern Michigan," Journal of Wildlife Management, vol. 40, pp. 317-325, 1976.

[17] D. F. Reed, "Conflicts with civilization," in Mule and BlackTailed Deer of North America, O. C. Walmo, Ed., pp. 509-545, University of Nebraska Press, Lincoln, Neb, USA, 1981.
[18] L. A. Romin and J. A. Bissonette, “Temporal and spatial distribution of highway mortality of mule deer on newly constructed roads at Jordanelle Reservoir, Utah," Great Basin Naturalist, vol. 56, no. 1, pp. 1-11, 1996.

[19] J. A. Bissonette and S. Rosa, "An evaluation of a mitigation strategy for deer-vehicle collisions," Wildlife Biology, vol. 18, no. 4, pp. 414-423, 2012.

[20] J.-M. Gaillard, M. Festa-Bianchet, N. G. Yoccoz, A. Loison, and C. Toïgo, "Temporal variation in fitness components and population dynamics of large herbivores," Annual Review of Ecology and Systematics, vol. 31, pp. 367-393, 2000.

[21] J.-M. Gaillard, M. Festa-Bianchet, and N. G. Yoccoz, "Population dynamics of large herbivores: variable recruitment with constant adult survival," Trends in Ecology and Evolution, vol. 13, no. 2, pp. 58-63, 1998.

[22] J. G. Kie and B. Czech, "Mule and black-tailed deer," in Ecology and Management of Large Mammals in North America, S. Demarais and P. R. Krausman, Eds., pp. 629-657, Prentice Hall, Upper Saddle River, NJ, USA, 2000.

[23] J. W. Unsworth, D. F. Pac, G. C. White, and R. M. Bartmann, "Mule deer survival in Colorado, Idaho, and Montana," Journal of Wildlife Management, vol. 63, no. 1, pp. 315-326, 1999.

[24] G. C. White, D. J. Freddy, R. B. Gill, and J. H. Ellenberger, "Effect of adult sex ratio on mule deer and elk productivity in Colorado," The Journal of Wildlife Management, vol. 65, no. 3, pp. 543-551, 2001.

[25] W. L. Robinette, N. V. Hancock, and D. A. Jones, The Oak Creek Mule Deer Herd in Utah, Utah Division of Wildlife Resources, Salt Lake City, Utah, USA, 1977.

[26] J.-M. Gaillard, A. Viallefont, A. Loison, and M. Festa-Bianchet, "Assessing senescence patterns in populations of large mammals," Animal Biodiversity and Conservation, vol. 27, no. 1, pp. 47-58, 2004.

[27] W. L. Robinette and J. S. Gashwiler, "Breeding season, productivity, and fawning period of the mule deer in Utah," Journal of Wildlife Management, vol. 14, pp. 457-469, 1950.

[28] J. S. Dixon, "A study of life history and food habits of mule deer in California," California Fish and Game, vol. 20, pp. 1-146, 1934.

[29] W. L. Robinette, D. A. Jones, G. Rogers, and J. S. Gashwiler, "Notes on tooth development and wear for Rocky Mountain mule deer," Journal of Wildlife Management, vol. 21, pp. 134-153, 1957.

[30] V. Veiberg, L. E. Loe, A. Mysterud, E. J. Solberg, R. Langvatn, and N. C. Stenseth, "The ecology and evolution of tooth wear in red deer and moose," Oikos, vol. 116, no. 11, pp. 1805-1818, 2007.

[31] E. J. Solberg and B.-E. Sæther, "Male traits as life-history variables: annual variation in body mass and antler size in moose (Alces alces)," Journal of Mammalogy, vol. 75, no. 4, pp. 1069-1079, 1994.

[32] C. M. Rolandsen, E. J. Solberg, I. Herfindal, B. van Moorter, and B.-E. Sæther, "Large-scale spatiotemporal variation in road mortality of moose: is it all about population density?" Ecosphere, vol. 2, article art113, 2011.

[33] A. Mysterud, "Temporal variation in the number of car-killed red deer Cervus elaphus in Norway," Wildlife Biology, vol. 10, no. 3, pp. 203-211, 2004.

[34] S. Ciuti, J. M. Northrup, T. B. Muhly et al., "Effects of humans on behaviour of wildlife exceed those of natural predators in a landscape of fear," PLoS ONE, vol. 7, no. 11, Article ID e50611, 2012. 
[35] K. M. Stewart, R. T. Bowyer, J. G. Kie, and M. A. Hurley, "Spatial distributions of mule deer and North American elk: resource partitioning in a sage-steppe environment," The American Midland Naturalist, vol. 163, no. 2, pp. 400-412, 2010.

[36] M. J. Wisdom, N. J. Cimon, B. K. Johnson, E. O. Garton, and J. W. Thomas, "Spatial partitioning by mule deer and elk in relation to traffic," in Transactions of the 69th North American Wildlife and Natural Resources Conference, pp. 509530, Wildlife Management Institute, Spokane, Wash, USA, 2004.

[37] G. R. Rost and J. A. Bailey, "Distribution of mule deer and elk in relation to roads," Journal of Wildlife Management, vol. 43, pp. 634-641, 1979.

[38] R. A. Montgomery, G. J. Roloff, and J. J. Millspaugh, "Variation in elk response to roads by season, sex, and road type," The Journal of Wildlife Management, vol. 77, no. 2, pp. 313-325, 2013.

[39] J. C. Tull and P. R. Krausman, "Habitat use of a fragmented landscape by females in a small population of desert mule deer," Southwestern Naturalist, vol. 52, no. 1, pp. 104-109, 2007.

[40] R. R. Lopez, M. E. P. Vieira, N. J. Silvy, P. A. Frank, S. W. Whisenant, and D. A. Jones, "Survival, mortality, and life expectancy of Florida key deer," Journal of Wildlife Management, vol. 67, no. 1, pp. 34-45, 2003.

[41] C. Peterson and T. A. Messmer, "Biological consequences of winter-feeding of mule deer in developed landscapes in northern Utah," Wildlife Society Bulletin, vol. 35, no. 3, pp. 252260, 2011.

[42] W. J. McShea, C. M. Stewart, L. J. Kearns, S. Liccioli, and D. Kocka, "Factors affecting autumn deervehicle collisions in a rural Virginia County," Human-Wildlife Conflicts, vol. 2, pp. 110121, 2008.

[43] T. L. Bashore, W. M. Tzilkowski, and E. D. Bellis, "Analysis of deer-vehicle collision sites in Pennsylvania," Journal of Wildlife Management, vol. 49, pp. 769-774, 1985.

[44] A. J. DeNicola and S. C. Williams, "Sharpshooting suburban white-tailed deer reduces deer-vehicle collisions," HumanWildife Interactions, vol. 2, pp. 28-33, 2008.

[45] T. R. McCabe and R. E. McCabe, "Recounting whitetails past," in The Science of Overabundance: Deer Ecology and Population Management, W. J. McShea, H. B. Underwood, and J. H. Rappole, Eds., pp. 11-26, Smithsonian Institution Press, Washington, DC, USA, 1997.

[46] M. F. McClure, J. A. Bissonette, M. R. Conover, and D. D. Austin, "Range expansion of white-tailed deer (Odocoileus virginianus) into urban and agricultural areas of Utah," Great Basin Naturalist, vol. 57, no. 3, pp. 278-280, 1997.

[47] P. W. West, UDOT Wildlife and Domestic Animal Accident Toolkit, vol. 67, Utah Department of Transportation, Salt Lake City, Utah, USA, 2008.

[48] R. R. Gillies and R. D. Ramsey, "Climate of Utah," in Rangelands Resources of Utah, R. E. Banner, B. D. Baldwin, and E. I. Leydsman McGinty, Eds., pp. 39-45, Utah State University Cooperative Extension Service, Logan, Utah, USA, 2009.

[49] A. L. Fisher, "Physical geography of Utah", 2013, http://historytogo.utah.gov/utah_chapters/the_land/physicalgeographyofutah .html.

[50] E. I. L. McGinty and C. M. McGinty, "Physiography of Utah," in Rangelands Resources of Utah, R. E. Banner, B. D. Baldwin, and E. I. L. McGinty, Eds., pp. 24-28, Utah State University Cooperative Extension Service, Logan, Utah, USA, 2009.
[51] G. E. Griffith and J. M. Omernik, "Ecoregions of Utah (EPA)," in The Encyclopedia of Earth, 2013, http://www.eoearth .org/view/article/152226/.

[52] S. L. Welsh, A. N. Atwood, and L. C. Higgins, Eds., A Utah Flora, Brigham Young University, Provo, Utah, USA, 1993.

[53] H. H. Bernales, K. R. Hersey, and A. Aoude, Utah Big Game Annual Report 2011, Utah Division of Wildlife Resource, Salt Lake City, Utah, USA, 2011.

[54] E. I. Leydsman McGinty, "Land ownership of Utah," in Rangelands Resources of Utah. Logan, R. E. Banner, B. D. Baldwin, and E. I. Leydsman McGinty, Eds., pp. 9-23, Utah State University Cooperative Extension Service, Logan, Utah, USA, 2009.

[55] E. I. Leydsman McGinty, "Urbanization in Utah," in Rangelands Resources of Utah, R. E. Banner, B. D. Baldwin, and E. I. Leydsman McGinty, Eds., pp. 153-156, Utah State University Cooperative Extension Service, Logan, Utah, USA, 2009.

[56] U.S. Census Bureau, Resident population data, 2010, http://www.census.gov/2010census/data/.

[57] UDOT, "Vehicle miles of travel," Utah Department of Transportation, 2010, http://www.udot.utah.gov/.

[58] C. Pope and A. McEwan, 2012 UDOT Annual Statistical Summary, Utah Department of Transportation, Salt Lake City, Utah, USA, 2012.

[59] J. A. Bissonette, C. Kassar, and L. J. Cook, "Assessment of costs associated with deer-vehicle collisions: human death and injury, vehicle damage, and deer loss," Human Wildlife Conflicts, vol. 2, no. 1, pp. 17-27, 2008.

[60] S. E. Thompson, Sampling, John Wiley \& Sons, New York, NY, USA, 1992.

[61] R Development Core Team, R: A Language and Environment for Statistical Computing, Reference Index Version 2.14.1, R Foundation for Statistical Computing, Vienna, Austria, 2012, http://www.r-project.org/.

[62] J. A. Erickson and W. G. Seliger, "Efficient sectioning of incisors for estimating ages of mule deer," The Journal of Wildlife Management, vol. 33, no. 2, pp. 384-388, 1969.

[63] K. L. Hamlin, D. F. Pac, C. A. Sime, R. M. DeSimone, and G. L. Dusek, "Evaluating the accuracy of ages obtained by two methods for Montana ungulates," The Journal of Wildlife Management, vol. 64, no. 2, pp. 441-449, 2000.

[64] Utah AGRC, Roads and Highway System, Utah Automated Geographic Reference Center, 2012, http://gis.utah.gov/.

[65] UDOT, Traffic on Utah's highways, Utah Department of Transportation, 2012, http://www.udot.utah.gov/.

[66] E. D. Bellis and H. B. Graves, "Deer mortality on a Pennsylvania interstate highway," Journal of Wildlife Management, vol. 35, pp. 232-237, 1971.

[67] M. E. Lehnert, J. A. Bissonette, and J. W. Haefner, "Deer (Cervidae) highway mortality: using models to tailor mitigative efforts," Gibier Faune Sauvage, Game Wildlife, vol. 15, pp. 835841, 1998.

[68] G. A. Goodwin and A. L. Ward, Mule Deer Mortality on Interstate 80 in Wyoming: Causes, Patterns, and Recommendations, Rocky Mountain Forest and Range Experiment Station, Fort Collins, Colo, USA, 1976.

[69] L. R. Jahn, "Highway mortality as an index of deer-population change," Journal of Wildlife Management, vol. 23, pp. 187-197, 1959.

[70] M. Hurley and P. Zager, Southeast Mule Deer Ecology, Idaho Fish and Game, Boise, Idaho, USA, 2007. 
[71] F. M. Slater, "An assessment of wildlife road casualties-the potential discrepancy between numbers counted and numbers killed," Web Ecology, vol. 3, pp. 33-42, 2002.

[72] D. D. Olson and J. A. Bissonette, The Olson-Bissonette Report for Vehicle-Related Mortality of Mule Deer in Utah, Utah State University, Logan, Utah, USA, 2013.

[73] A. Danilkin, Behavioural Ecology of Siberian and European Roe Deer, Springer, New York, NY, USA, 1995.

[74] M. J. Wisdom and J. G. Cook, "North American elk," in Ecology and Management of Large Mammals in North America, S. Demarais and P. R. Krausman, Eds., pp. 694-735, Prentice Hall, Upper Saddle River, NJ, USA, 2000.

[75] M. M. Rowland, M. J. Wisdom, B. K. Johnson, and M. A. Penninger, "Effects of roads on elk: implications for management in forested ecosystems," in The Starkey Project: A Synthesis of Long-Term Studies of Elk and Mule Deer, M. J. Wisdom, Ed., pp. 42-52, Alliance Communications, Lawrence, Kan, USA, 2005.

[76] H. Sawyer, M. J. Kauffman, R. M. Nielson, and J. S. Horne, "Identifying and prioritizing ungulate migration routes for landscape-level conservation," Ecological Applications, vol. 19, no. 8, pp. 2016-2025, 2009.

[77] H. Sawyer, R. M. Nielson, F. Lindzey, and L. L. McDonald, "Winter habitat selection of mule deer before and during development of a natural gas field," Journal of Wildlife Management, vol. 70, no. 2, pp. 396-403, 2006.

[78] R. G. D’Eon and R. Serrouya, "Mule deer seasonal movements and multiscale resource selection using global positioning system radiotelemetry," Journal of Mammalogy, vol. 86, no. 4, pp. 736-744, 2005.

[79] P. E. Lendrum, C. R. Anderson, R. A. Long, J. G. Kie, and R. T. Bowyer, "Habitat selection by mule deer during migration: effects of landscape structure and natural-gas development," Ecosphere, vol. 3, Article ID art82, 2012.

[80] E. D. Anderson, R. A. Long, M. P. Paul Atwood et al., "Winter resource selection by female mule deer Odocoileus hemionus: functional response to spatio-temporal changes in habitat," Wildlife Biology, vol. 18, no. 2, pp. 153-163, 2012.

[81] K. M. Stewart, R. T. Bowyer, J. G. Kie, N. J. Cimon, and B. K. Johnson, "Temporospatial distributions of elk, mule deer, and cattle: resource partitioning and competitive displacement," Journal of Mammalogy, vol. 83, pp. 229-244, 2002.

[82] R. T. Bowyer, J. G. Kie, and V. van Ballenberghe, "Habitat selection by neonatal black-tailed deer: climate, forage, or risk of predation?" Journal of Mammalogy, vol. 79, no. 2, pp. 415-425, 1998.

[83] R. A. Long, J. G. Kie, R. Terry Bowyer, and M. A. Hurley, "Resource selection and movements by female mule deer Odocoileus hemionus: effects of reproductive stage," Wildlife Biology, vol. 15, no. 3, pp. 288-298, 2009.

[84] B. K. Johnson, J. W. Kern, M. J. Wisdom, S. L. Findholt, and J. G. Kie, "Resource selection and spatial separation of mule deer and elk during spring," The Journal of Wildlife Management, vol. 64, no. 3, pp. 685-697, 2000.

[85] D. D. Olson and J. A. Bissonette, "How does winter weather affect deer-vehicle collision rates?," Wildlife Biology, In press.

[86] D. R. Mccullough, "Density dependence and life-history strategies of ungulates," Journal of Mammalogy, vol. 80, no. 4, pp. 1130-1146, 1999.

[87] P. Cramer and J. Bissonette, "Wildlife crossings in North America," in Proceedings of the Transportation Research Board Wildlife and Highways Workshop, Washington, DC, USA, January 2006, http://digitalcommons.usu.edu/wild_facpub/1206/.
[88] P. Cramer, "Determining wildlife use of wildlife crossing structures under different scenarios," Tech. Rep. UT-12.07, Utah State University, Logan, Utah, USA, 2012. 

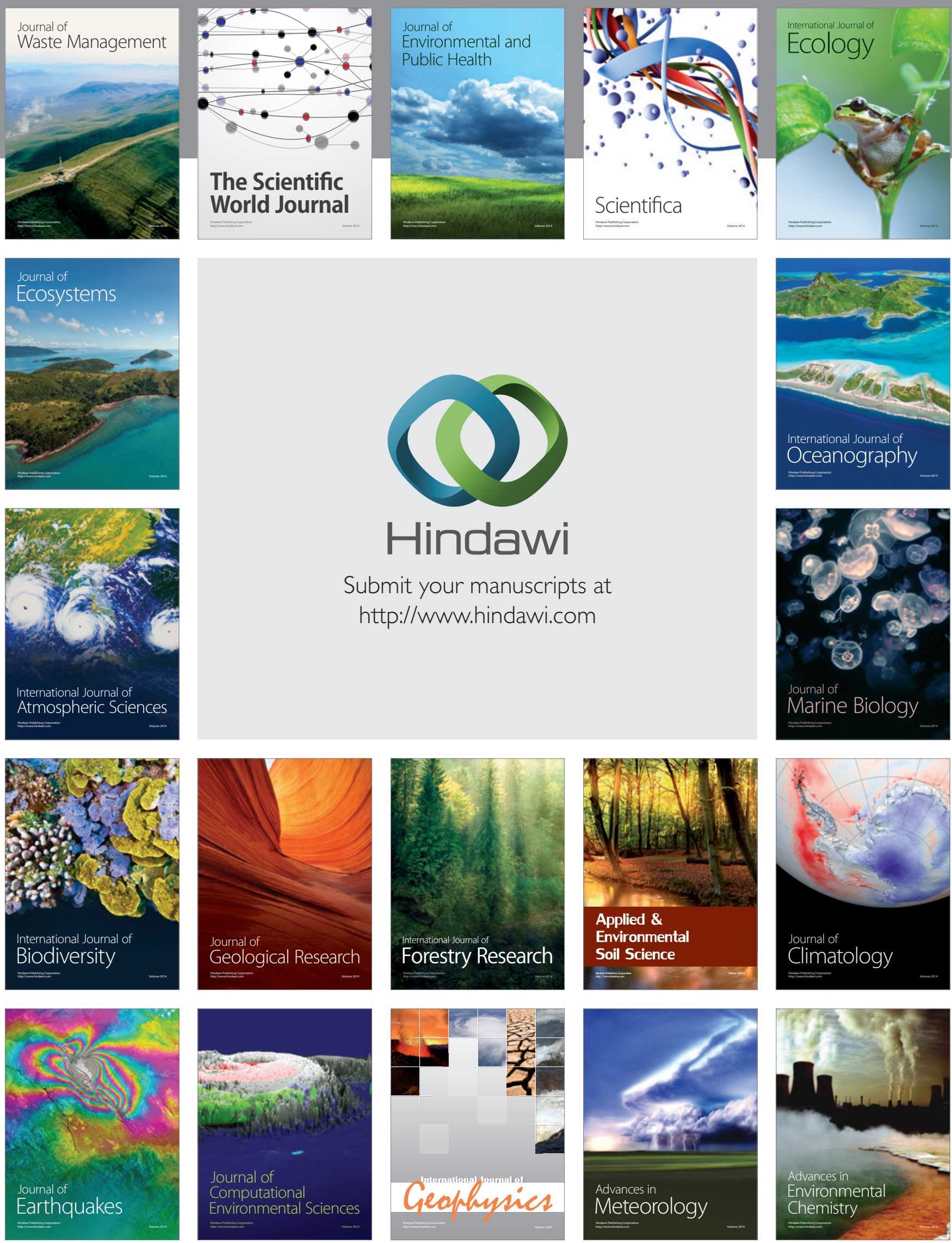